\title{
Fatores Associados à não Adaptação do Bebê na Creche: da Gestação ao Ingresso na Instituição
}

\author{
Gabriela Dal Forno Martins ${ }^{1}$ \\ Universidade Federal do Rio Grande \\ Scheila Machado da Silveira Becker \\ Lívia Caetano da Silva Leão \\ Rita de Cássia Sobreira Lopes \\ Cesar Augusto Piccinini \\ Universidade Federal do Rio Grande do Sul
}

\begin{abstract}
RESUMO - Buscou-se identificar fatores associados à não adaptação do bebê na creche, tais como, temperamento do bebê, relações pais-bebê e crenças e práticas ligadas aos cuidados alternativos. Participaram quatro famílias, cujos bebês entraram na creche entre 10 e 12 meses de idade e foram retirados por não adaptação segundo avaliação dos pais. Realizou-se entrevistas na gestação, 3, 8 e 12 meses do bebê. Análise de conteúdo qualitativa revelou que os fatores mais relevantes na compreensão da não adaptação relacionaram-se à dinâmica da interação pais-bebê, a saber: sentimentos ligados à separação e forma com que os pais vivenciaram o ingresso na creche. Os resultados sugerem a importância de ações que promovam acolhimento à situação de separação pais-bebê na transição para a creche.
\end{abstract}

Palavras-chave: creche, adaptação do bebê, relação pais-bebê, psicologia

\section{Factors Associated with the not Adjusting of Babies to Daycare: From Pregnancy to Daycare Entrance}

\begin{abstract}
We aimed to identify factors associated with the not adjusting of babies to daycare, such as, baby's temperament, parents-baby relationship and beliefs and practices about alternative care. Participants were four families whose babies entered into daycare between 10 and 12 months of age and were removed by not adjusting as evaluated by their parents. Interviews were applied during pregnancy, and when the baby was three, eight and twelve months old. Qualitative content analysis indicated that the most relevant factors to understand the not adjustment were related to dynamics of parents-baby interaction, like: feelings related to separation and the way that parents experienced daycare center entrance. The results highlight the importance of promoting the acceptance of parents-baby separation in transition to daycare.
\end{abstract}

Keywords: adjustment of babies to daycare, parents-baby separation, case study

De maneira geral, parece haver um consenso entre profissionais e pais sobre a importância de que os primeiros dias de um bebê na creche precisam ser tratados de maneira especial para facilitar a sua adaptação. No Brasil, o Referencial Curricular para a Educação Infantil (Brasil, $\mathrm{MEC} / \mathrm{SEF}, 1998$ ) sugere a presença de familiares durante o período de adaptação, uma inserção gradual da criança na creche e o respeito à variabilidade do tempo de adaptação de cada criança. Embora diretrizes gerais para a atuação dos profissionais, já estejam bem consolidadas, a complexidade do momento de transição família-creche traduz-se em desafios sutis de como lidar com as especificidades de cada caso.

Essa complexidade se expressa, por exemplo, na dificuldade de definição do próprio conceito de adaptação. Por exemplo, Aloa (2008) chamou atenção para duas dimensões do conceito: 1) adaptação como transição famíliacreche, que envolve o processo de mudança no contexto

1 Endereço para correspondência: Universidade Federal do Rio Grande. Campus de Santo Antônio da Patrulha. Rua Barão do Cahy, 125. Sala 12. Santo Antônio da Patrulha, RS, Brasil, CEP: 95500-000. E-mail gabriela.martins@furg.br de desenvolvimento da criança e nas relações pais-bebê; e 2) adaptação como o resultado esperado na criança após o período de transição. O presente estudo focaliza em especial a primeira dimensão, a adaptação como transição família-creche. Para Strenzel (2002), a transição tem sido entendida como um processo que se inicia quando os pais efetivam a matrícula de sua criança. Já para Ferreira (2007), esta ocorreria quando os pais passam a vislumbrar mais concretamente a entrada da criança na creche. No entanto, acredita-se que uma análise mais completa desse processo deve incluir a história pregressa da relação pais-bebê, uma vez que desde a gestação os pais já possuem expectativas sobre a futura relação com o filho (Piccinini, Gomes, Moreira, \& Lopes, 2004) e sobre a possibilidade de inseri-lo em algum tipo de cuidado alternativo (Rapoport, 2003).

Em consonância com essa concepção, alguns autores (Rapoport \& Piccinini, 2001a; Rossetti-Ferreira, Amorim, \& Vitória, 1996) ressaltam que a qualidade da adaptação à creche depende de três principais fatores: 1) características da criança; 2) contexto de cuidado familiar, especialmente a qualidade da interação com a mãe ou cuidador principal; e 3) qualidade da creche e da relação que o educador estabelece com a criança. No que se refere à própria criança, a idade com 
que ingressa na instituição pode interferir na adaptação. Por exemplo, bebês que entram na creche no primeiro semestre de vida tendem a apresentar menor incidência de protestos (Kearsley, Zelazo, Kagan, \& Hartman, 1975, Rodriguez, 1981), enquanto que bebês entre 9 e 12 meses tendem a levar mais tempo para se adaptarem e demonstram mais estresse quanto à entrada na creche (Aloa, 2008).

O temperamento do bebê também tem sido considerado um fator de influência neste momento de transição (Ahnert, Gunnar, Lamb, \& Barthel, 2004; Fein, 1995; Klein, 1991; Rapoport \& Piccinini, 2001b). Segundo Aloa (2008), o temperamento reflete a forma individual com que cada criança reage e se adapta a novas situações e experiências. Algumas crianças com temperamento difícil estariam predispostas a dificuldades de adaptação à creche, mesmo naquelas de alta qualidade, com educadoras sensíveis e responsivas (Fein, 1995).

O temperamento infantil também tem sido associado ao apego, e o estudo de Ahnert et al. (2004) revelou que crianças com apego seguro foram percebidas pela mãe como mais acessíveis e adaptáveis a novas situações (ex. creche) do que crianças com apego inseguro. Assim, é importante considerar as percepções parentais sobre o temperamento do bebê, uma vez que são cruciais para definir se o temperamento será ou não um empecilho à adaptação (Aloa, 2008).

As experiências prévias da criança no contexto familiar configuram outro conjunto de fatores associados à adaptação à creche. Bebês que têm irmãos ou convivem com outras crianças parecem mais hábeis para lidar com as especificidades de ter mais crianças no ambiente (Aloa, 2008). Além disso, crianças que foram cuidadas por outras pessoas que não apenas o cuidador primário (comumente a mãe) parecem adaptar-se com maior facilidade (Aloa, 2008; Blanchard \& Main, 1979; Schipper, Van Ijzendoorn, \& Tavecchio, 2004).

Mais especificamente, a qualidade prévia da interação mãe-bebê é um fator que vem sendo destacado na literatura. Por exemplo, no estudo de Ahnert et al. (2004) referido acima, foi investigada a influência do apego na manifestação de estresse pela criança durante seus primeiros meses na creche. Os autores verificaram que bebês com apego seguro exibiram níveis de cortisol menos elevados na fase inicial de permanência na creche, quando a mãe ainda permanecia em sala, sendo interpretado como indicativo de que, para esses bebês, a presença da mãe pode ter efeito neutralizador sobre o estresse vivenciado nos primeiros dias.

Ainda, o modo como pais e bebês vivenciam separações e o significado que eles atribuem à entrada da criança na creche pode influenciar a adaptação (Burchinal, Bryant, Lee, \& Ramey, 1992; Ferreira, 2007). Para algumas mães, a creche passa a ser considerada como opção mais concreta por volta de um ano da criança, impulsionadas tanto pela maior autonomia do bebê, quanto pelo desejo da mãe de retomar a suas atividades profissionais e como forma de retomar seus espaços pessoais (Bellini, 2008). Nesse sentido, quando os pais estão felizes e confortáveis com sua escolha, tendem a confiar mais nas educadoras, de modo que a criança fica mais tranquila na creche (Aloa, 2008; Rapoport \& Piccinini, 2001b, Rossetti-Ferreira et al., 1996).
Por fim, a boa qualidade do atendimento na creche (interação cuidador-bebê, estabilidade dos cuidados, razão adulto-criança) tem sido relatada como um importante aspecto que pode facilitar ou dificultar a adaptação (Howes, 1990, Schipper et al., 2004). Entre diversas estratégias para facilitar a transição para a creche, tem-se destacado a importância das visitas à creche antes do ingresso da criança, para que ela se familiarize com o ambiente e com as educadoras (Aloa, 2008).

Sem desconsiderar a influência da qualidade da creche na adaptação, esse estudo buscou explorar particularmente as experiências subjetivas dos pais no que se refere ao ingresso da criança na creche, desde a gestação até a entrada na educação infantil.

Assim, teve-se como objetivo identificar fatores associados à não adaptação do bebê na creche, com destaque para as características do temperamento do bebê, as relações pais-bebê e os sentimentos ligados a separações entre eles e as crenças e práticas ligadas a cuidados alternativos, incluindo a creche. Mais especificamente, pretendeu-se compreender como esses fatores se articulam ao longo do desenvolvimento do bebê e contribuem para a escolha pelo ingresso do bebê na creche e para sua não permanência nesse contexto.

\section{Método}

\section{Participantes}

Participaram do estudo três casais e uma mãe solteira, cujos filhos saíram de creches privadas por terem apresentado dificuldades na adaptação, segundo a avaliação dos pais. Todos participaram do Estudo Longitudinal de Porto Alegre: Da Gestação à Escola - ELPA (Piccinini, Tudge, Lopes, \& Sperb, 2009) aprovado pela Comissão de Pesquisa e Ética em Saúde do Hospital de Clínicas de Porto Alegre. O estudo iniciou acompanhando 81 famílias, da gestação aos oito anos de vida da criança, e teve por objetivo investigar aspectos subjetivos e comportamentais das interações iniciais paimãe-bebê e o impacto de fatores iniciais do desenvolvimento nas interações familiares, no comportamento social de crianças pré-escolares e na transição para a escola de ensino fundamental. Para escolha dos participantes do presente estudo foram identificados todos os casos em que o bebê havia sido retirado da creche devido à manifestação de sinais de não adaptação, tais como choro, adoecimento, agressividade etc. (Aloa, 2008; Rapoport \& Piccinini 2001a, 2001b).

As mães, participantes do presente estudo, tinham na gestação, idades entre 19 e 27 anos e níveis de escolaridade desde Ensino Fundamental incompleto até Superior Incompleto. Os pais possuíam idades entre 18 e 27 anos durante a gestação e escolaridade entre o Ensino Fundamental Completo e Superior Incompleto. Todos os pais e mães trabalhavam, sendo que duas mães eram donas de casa. Dois bebês eram do sexo masculino, todos entraram na creche no segundo semestre de vida (entre 10 e 12 meses) e o tempo de permanência na creche variou entre 1 e 8 semanas. 


\section{Delineamento, procedimentos e instrumentos}

Foi utilizado um delineamento de estudo de caso coletivo (Stake, 1994), de caráter longitudinal, a partir de dados da gestação, três e oito meses do bebê (períodos anteriores ao ingresso na creche) e do décimo segundo mês do bebê (fase posterior à saída). Seguindo as fases de coleta de dados do ELPA, no terceiro trimestre de gestação, as famílias foram convidadas a participar do projeto e as que aceitaram foram visitadas em suas residências. Nesta ocasião, foram preenchidos o Termo de Consentimento Livre e Esclarecido e realizadas a Entrevista de Dados Demográficos (GIDEP, 1998a), a Entrevista sobre a Gestação e Expectativas da Gestante (GIDEP, 1998b) e a Entrevista sobre a Gestação e as Expectativas do Futuro Pai (GIDEP, 1998c).

No terceiro mês após o nascimento da criança, aplicaramse, nas residências das famílias, a Ficha de Impressões dos Pais sobre o Temperamento da Criança (GIDEP, 1999a), a Entrevista sobre a Experiência da Maternidade e o Desenvolvimento do Bebê no Primeiro Trimestre (GIDEP, 1999b) e a Entrevista sobre a Experiência da Paternidade e o Desenvolvimento do Bebê no Primeiro Trimestre (GIDEP, 1999c). Finalmente, no oitavo e décimo segundo mês do bebê, as famílias compareceram ao Instituto de Psicologia da Universidade Federal do Rio Grande do Sul - UFRGS, onde foram aplicados os mesmos instrumentos do terceiro mês adaptados para a faixa etária.

Os dados foram analisados através de análise de conteúdo qualitativa (Bardin, 1977; Laville \& Dionne, 1999), utilizando-se o Software Nvivo8. Para tanto, as respostas dos pais a todas as entrevistas foram lidas integralmente e classificadas em categorias temáticas, definidas a priori a partir da literatura sobre fatores associados à adaptação do bebê à creche (Aloa, 2008; Rapoport \& Piccinini 2001a, 2001b).

As seguintes categorias foram utilizadas: 1) Temperamento do bebê: refere-se às impressões dos pais sobre o bebê e relatos a respeito das diversas dimensões de seu temperamento (não utilizada na gestação); 2) Sentimentos dos pais ligados à separação pais-bebê e à inclusão de outras pessoas no dia a dia da criança: refere-se aos sentimentos frente a episódios de separação do bebê, que não aqueles relacionados ao ingresso da criança na creche; 3) Crenças e práticas parentais relacionados a outros cuidados alternativos: refere-se à inclusão ou não de outras pessoas nos cuidados ao bebê e a avaliação dos pais sobre esses cuidados; 4) Atitudes dos pais em relação à creche: refere-se às expectativas, crenças e sentimentos dos pais ligados à creche como possibilidade futura de cuidado; e, 5) Sentimentos dos pais relacionados ao ingresso do bebê na creche: refere-se aos sentimentos despertados depois que o bebê passou a frequentar a instituição. Dois juízes classificaram separadamente os relatos de todos os pais em cada categoria e, em caso de discordância, um terceiro juiz foi consultado.

\section{Resultados}

Apresentam-se, a seguir, os resultados separadamente por caso, seguindo a mesma estrutura de categorias descrita acima. As mudanças longitudinais foram analisadas dentro de cada categoria e vinhetas ilustraram os relatos dos pais.

\section{Caso 1 - "Bebê-sol, pais-planetas"}

Caracterização: Lucas ${ }^{1}$, primeiro filho do casal (mãe, 19 anos, ensino médio completo, dona de casa. Pai, 27 anos, ensino médio completo, atendente de lotérica), foi colocado na creche aos 10 meses, pois os pais percebiam que suas habilidades estavam além do que o ambiente familiar possibilitava desenvolver. Lucas reagiu bem à primeira semana na creche, período em que a mãe permaneceu na instituição. Quando ficou sozinho, os pais relataram que passou a chorar muito, não aceitar alimentos, adoeceu e não ganhou peso. Com isso, somado à sugestão do pediatra, após aproximadamente dois meses os pais decidiram que ele voltaria a ficar em casa com a mãe. Afirmaram valorizar muito a família e estar dispostos a abrir mão de atividades de lazer e profissionais em função do filho: "Tudo gira em torno dele, ele é o sol e nós somos os planetas. Ele que decide o que ele quer e a gente só vai correndo atrás" (pai).

Temperamento do bebê: Desde o terceiro mês os pais forneceram indicadores de que o bebê possuía um temperamento difícil. Enfatizaram a intensidade do choro e a instabilidade no humor: "Tem dias que ele está de mau humor. Ele pode estar no meu colo, ela (mãe) vem brincar com ele e ele chora. Vem qualquer pessoa, ele chora. Então dai tem que deixar ele mais sozinho" (pai). Quando o bebê chorava, a única forma de acalmá-lo era no peito, o que fazia com que ele não tivesse horários regulares para as mamadas. Ele também não reagia bem ao contato com outras pessoas: "Ele começa a fazer beicinho e já abre aquela choradeira" (mãe); assim como a lugares estranhos e mudanças na rotina: "Ele gosta mais é de ficar sozinho. Só conosco em casa" (mãe). Por outro lado, os pais afirmaram que ele dormia bem, gostava do banho e aceitava a troca de roupas.

$\mathrm{Na}$ entrevista do oitavo mês, os pais continuaram descrevendo-o como difícil: "Bravo, mal-humorado. Eu acho que ele é muito irritado, muito nervosinho, você diz não, ele já resmunga e grita e se endurece" (mãe). A mãe destacou que o bebê se acalmava quando recebia atenção ou estava no colo dos pais. Lucas se mostrou agitado durante a troca de fraldas e roupas, seu sono era inquieto e só dormia no peito. Quanto à alimentação, o bebê agitava-se, não aceitava bem os alimentos e não possuía horários regulares.

Sentimentos ligados à separação pais-bebê e à inclusão de outras pessoas no dia a dia da criança: Na gestação, a mãe manifestou preocupação com os momentos de separação entre ela e o bebê: "Ela disse para mim: 'Quando nascer, não desgruda dele, fica com ele o tempo todo, não o deixa enquanto nós não formos embora"' (pai). Já aos 3 meses, a mãe relatou sentir ciúmes e saudade quando as visitas pegavam o bebê no colo e não gostar de dividir os cuidados do filho: "Eu gosto de eu dar banho, de eu trocar fralda,

1 Todos os nomes apresentados são fictícios 
eu quero ser a mãe completa. Eu não gosto de deixar para os outros".

No oitavo mês, o pai disse que nunca precisou se afastar do filho por muito tempo e esperava que isso não acontecesse, pois sentia muita saudade, ainda que achasse importante se distanciar: "Tem que saber dosar, mas ainda está meio dificil". A mãe também expôs sua dificuldade: "Eu gosto de estar sempre com ele. Até o meu marido já estava querendo sair e deixar ele com a avó. Mas eu ainda não estou em condições de largá-lo”.

Crenças e práticas parentais relacionadas a outros cuidados alternativos: $\mathrm{Na}$ gestação, a mãe e o pai concordavam que não queriam deixar o filho sob o cuidado de parentes: "Acho que a família mima demais e estraga a criança, porque a família faz todas as vontades” (mãe). Tanto aos 3, quanto aos 8 meses do bebê, não havia ninguém ajudando a cuidá-lo: "Vai junto, volta do serviço junto, nós vamos sair, ele vai junto. Não o deixamos com ninguém” (pai).

Aos 8 meses, a mãe ainda não se afastava do bebê por muito tempo, apenas em algumas saídas rápidas, quando o deixava com o marido ou com a sogra. No entanto, passou a dar sinais de que gostaria de dividir as tarefas com outras pessoas: "Acho que está sendo difícil para mim, por ser tudo comigo”.

Atitudes em relação à creche: $\mathrm{Na}$ gestação, o casal apresentava uma atitude favorável à creche: "Queremos deixá-lo numa creche, que lá ele aprende a conviver com outras crianças" (mãe); "Com certeza ele vai para a creche. Eu acho que com uns três anos" (pai). Aos 3 meses, a mãe mostrou uma atitude ambivalente em relação à creche, pois considerava a possibilidade de colocá-lo, caso voltasse a trabalhar, mas questionava seus benefícios: "Numa creche eles botam muitas normas e deixam a criança cheia de responsabilidade muito novinha. Acho que não vale a pena o salário que eu vou ganhar para o que eu vou deixar de fazer por ele". Quanto ao pai, ele continuava favorável a colocar o filho na creche, mas imaginava que seria difícil o ingresso na instituição.

Finalmente, no oitavo mês, a mãe afirmou que pretendia colocá-lo na creche com aproximadamente 18 meses: "Quando ele já tiver aprendido a brincar com outras crianças". Imaginava que o bebê ficaria bem na creche, mas que para ela seria muito difícil: "Acho que eu vou ficar chorando em roda da creche, esperando ele sair, não vou conseguir fazer outra coisa". Já o pai mudou de opinião e disse que dificilmente seu filho iria para a creche: "Não sei se eu vou confiar nas pessoas que vão ficar com ele. Não conheço".

Sentimentos maternos e paternos relacionados ao ingresso do bebê na creche: Aos 12 meses, os pais relataram o quanto foi difícil deixar o bebê na creche: "Não conseguia parar de pensar um segundo nele. Não descontraía. Ligava para lá toda hora para saber como é que ele estava" (mãe). A mãe se mostrou arrependida: "Acho que eu não devia ter deixado. Aquelas tardes que ele ficou chorando lá. Acho que eu maltratei ele. Até pretendo colocar ele na escolinha. Mas quando ele estiver comendo de tudo, estiver falando. Mais independente. Agora ele ainda está muito dependente de mim, não dá para, simplesmente, eu pegar e largar ele”. Já o pai afirmou que "De repente, se nós insistíssemos mais, mas daí vem o lado do pai e mãe. Tu não quer aquilo. Então tu tenta arrumar uma outra solução. E a outra solução foi aquela. Contratamos uma funcionária e ele ficou com a mãe em casa”.

\section{Caso 2 - "Quer ficar de mal? Coloca ela na creche!"}

Caracterização: Flávia foi a primeira filha do casal (mãe, 21 anos, ensino superior incompleto, dona de casa. Pai, 25 anos, ensino superior incompleto, proprietário de comércio). Quando tinha 10 meses, ingressou na creche visando evitar sobrecarregar a mãe, que estava grávida, e para ter contato com outras crianças. Permaneceu por volta de uma semana e, segundo os pais, adaptou-se bem aos primeiros dias, manifestando tranquilidade e alegria. Porém, repentinamente, passou a chorar de forma intensa e por muito tempo, sem nenhuma explicação plausível. Ao perceber que Flávia continuava a chorar quando a deixavam na creche, decidiram por retirá-la.

Temperamento do bebê: Aos 3 e 8 meses do bebê, os pais descreviam a filha como possuindo, em geral, um temperamento fácil. Flávia aceitava bem os alimentos novos e estava sendo amamentada no peito, enquanto que aos 8 meses mamava somente no período da noite. Os pais relataram que a filha dormia bem, chorava pouco, não estranhava pessoas, tinha facilidade para se adaptar a lugares diferentes e a mudanças em sua rotina: "Ela quase não estranha. A pediatra que diz que ela é bem social, como ela gosta de evento" (mãe, 3 meses). Quanto ao humor da filha, de maneira geral, a descreviam como "Uma criança que não incomoda, tranquila, calma” (pai, 3 meses). No entanto, enfatizaram que, quando não conseguiam imediatamente atender suas necessidades, a menina mostrava-se brava: "Ela continua brava, ela quer as coisas que ela quer, não tem meio termo para ela" (pai, 8 meses). Os pais justificaram essa reação da filha em função da existência de várias pessoas disponíveis para ela: "Por ser só ela. Tudo o que dão é para ela, porque ela é a nenezinha do avô, o xodó da avó” (mãe, 3 meses). Por fim, aos oito meses do bebê, os pais relataram alguns indícios de ganho de autonomia, tais como comer na mesa com os pais, dormir no próprio berço e manifestar interesse em explorar o ambiente.

Sentimentos ligados à separação pais-bebê e à inclusão de outras pessoas no dia a dia com a criança: Tanto aos 3 , quanto aos 8 meses do bebê, a separação entre os pais e a criança não parecia suscitar sentimentos negativos nos mesmos. Apenas a mãe falou sobre a insegurança ao deixar a filha com outras pessoas: "No começo dá uma coisa, elas não estão fazendo do jeito que eu quero. Mas daí eu procuro não encucar muito"' (3 meses). O que mais mobilizava os pais era a sensação de intrusão dos familiares na sua rotina e na forma de educar a menina. O pai já parecia mais mobilizado aos 3 meses de Flávia e, aos 8 meses, o desconforto com os familiares também ficou mais evidente na mãe: " $E$ bom saber que eles estão juntos, que todos os avós curtem, mas às vezes seria melhor que não tivesse tanta interferência”. 
Na percepção da mãe, essa intromissão fazia com que ela e o marido se sentissem dependentes dos avós e pouco confiantes frente à criação da filha.

Crenças e práticas parentais relacionados a outros cuidados alternativos: Desde a gestação, já estava claro que os familiares ajudariam nos cuidados ao bebê: " $A$ minha mãe disse que se tiver que deixar com alguém, que deixe com ela" (mãe). Aos 3 meses, todos os avós participavam do dia a dia de Flávia. A mãe levava a filha para o local de trabalho e geralmente um dos avós as acompanhava nesse período. Também ficavam com a menina quando os pais saíam, ajudavam nas tarefas domésticas e quando os pais não sabiam lidar com alguma situação: "Às vezes, de noite, acontece alguma coisa, eu ligo para eles, e eles vêm correndo" (mãe). Apesar de reconhecerem a importância da ajuda dos avós, aos 3 meses, consideravam-na um pouco excessiva: "Tem coisas que são demais. Acho importante eles ajudarem, mas tem que ter um pouco de limite para as coisas" (pai). Aos 8 meses, Flávia continuava sendo cuidada pela mãe e pelos avós, embora o relato da mãe apresentasse indícios de predomínio dos cuidados maternos.

Atitudes em relação à creche: Na gestação, os pais não tinham uma ideia clara a respeito do momento de inseri-la na creche. A mãe enfatizou que "creche é caro", enquanto o pai mostrou-se favorável: "A gente pretende mais tarde colocar numa creche. Até para ter convívio com outras crianças". Aos 3 meses, os pais mostraram-se menos favoráveis à creche. A mãe não pensava em colocar a filha naquele momento por julgar que perderia a oportunidade de vê-la desenvolver-se, enquanto o pai estava certo de que não gostaria de colocar a filha: "Olha eu nunca pensei em colocar ela na creche, penso em colocar ela no colégio já” (pai).

$\mathrm{Na}$ entrevista de 8 meses, novamente houve uma mudança de atitude dos pais frente à creche. Como o ingresso da criança já estava previsto, a mãe enfatizou a possibilidade de Flávia conviver com outras crianças, ter mais atenção e uma rotina mais organizada: "Para ela ter convivência com outras crianças, porque no fim ela fica só comigo na loja, nem sempre eu posso dar atenção para ela”. Já o pai estava preocupado com a sobrecarga da esposa, grávida, além da pouca convivência da filha com outras crianças e com a interferência dos avós na sua criação, que eram contra o ingresso de Flávia na creche: "Se tu queres ficar de mal comigo tu botas ela na creche, esse tipo de coisa, apelando sabe?" (pai).

As interferências dos avós nesta decisão parecem ter repercutido nas expectativas dos pais, que demonstravam estar inseguros: "É ruim, porque dai eu me sinto como se eu fosse má, como se eu estivesse fazendo alguma coisa errada, porque eles (avós) têm experiência, mas têm que deixar a gente também, errar, aprender errando" (mãe). $\mathrm{O}$ pai enfatizou que a filha não tinha que se adaptar necessariamente: "Veremos se ela vai se adaptar. Ela não é obrigada a ficar na creche".

Sentimentos maternos e paternos relacionados ao ingresso do bebê na creche: Flávia permaneceu aproximadamente uma semana na creche, e embora sua reação inicial tenha sido positiva, passou a chorar sem motivo explícito e não mais querer ficar. Como a creche não forneceu aos pais uma explicação concreta para o choro, eles ficaram receosos e optaram por retirá-la naquele momento: "Eu perdi a confiança também na creche. Mas a gente vê que era um choro desesperado, não era uma manha. Ai achamos melhor botar quando ela estiver falando pelo menos" (pai).

\section{Caso 3 - "O bebê desamparado"}

Caracterização: Daiana era filha de um casal de namorados que havia rompido o namoro, pouco tempo antes de saber da gravidez (mãe, 19 anos, ensino fundamental incompleto, cuidadora de idoso e babá. Pai, 18 anos, ensino fundamental completo, serviços gerais). $O$ casal não reatou a relação com a gravidez e o pai não reconheceu a paternidade. Aos 10 meses da filha, Simone optou por colocá-la na creche, pois conseguira emprego em período integral. A menina permaneceu aproximadamente um mês na creche e, segundo Simone, "Não se adaptou, ela foi expulsa da creche". A mãe relatou que o bebê chorava intensamente, não comia e as educadoras não conseguiam de forma alguma acalmá-lo e relataram que temiam que os vizinhos denunciassem a creche por imaginarem que alguém estivesse maltratando a menina.

Temperamento do bebê: Aos 3 meses da filha, a mãe a percebia como tranquila, pouco chorona e bem humorada $\mathrm{e}$, às vezes, "muito brava". A menina aceitava bem o leite materno, mas não tinha horários definidos para a alimentação e sono, de modo que era a filha que se adaptava aos horários da mãe: "Muito difícil ela dormir durante o dia!"; "eu ando dormindo até tarde!". Quanto ao sono, embora geralmente tranquilo e ininterrupto, por vezes a filha acordava à noite e chorava com muita intensidade, a ponto dos vizinhos desconfiarem que a mãe batia na filha: "Às vezes ela grita, ela está chorando e grita ao mesmo tempo. A vizinha perguntou para a minha irmã: 'a tua irmã bate na guriazinha dela? Porque ela grita tanto que dá vontade de levantar de madrugada e vir pegá-la!'”. Simone acreditava que esse choro indicava fome, mas esperava até o choro tornar-se mais forte para atender a filha.

Com o passar dos meses esse mesmo padrão se fortaleceu. Aos 8 meses da filha, Simone a percebia com um temperamento difícil, que incluía agitação e choro excessivo. É possível que Daiana estivesse mais regredida e dependente da mãe: "Eu não estou [procurando emprego] porque ela não fica com ninguém. Eu quero sair para procurar, eu quero trabalhar, mas eu quero esperar ela fazer um ano". A falta de emprego da mãe provocou uma grande dificuldade financeira, que tornou Daiana mais dependente do leite materno: "Agora ela toma só do peito e eu consigo alimentá-la porque estou pegando leite em pó no posto para eu tomar. Mas falta a alimentação que ela tinha antes". O bebê continuava não tendo uma rotina para a alimentação.

Da mesma forma, a rotina do sono também parecia desorganizada, e continuava definida mais em função dos horários da mãe. $\mathrm{O}$ sono da filha era agitado e a menina estava dormindo pouco, padrão que a mãe relacionava com os períodos de doença ou então com momentos de agressividade 
dela com a filha: "Não vou mentir, é umas sacudidas que eu dou nela, porque ela me incomoda, fica enlouquecida, e às vezes eu estou brigada com outras pessoas e descarrego na Daiana"; e da agitação do ambiente familiar: "É por causa da gritaria no meu pátio, ela [avó materna] grita com a gente e a gente grita com ela. Então a Daiana fica presenciando tudo aquilo. Eu acho que ela fica nervosa".

Finalmente, Simone destacou a dificuldade da filha em lidar com momentos de separação: "Ela não deixa [a mãe sair], mas eu não fujo dela, eu sempre mostro que eu estou saindo”. Quando a mãe saía, geralmente Daiana ficava chorando e nem sempre as pessoas a atendiam prontamente, configurando momentos de bastante angústia para a menina. Ela também manifestava resistência frente a pessoas estranhas, e, segundo Simone, precisava de alguns dias ininterruptos de convivência para aceitar pessoas diferentes.

Sentimentos ligados à separação pais-bebê e à inclusão de outras pessoas no dia a dia da criança: Aos 3 meses do bebê, Simone relatou sentimentos de preocupação e angústia quando precisava ficar longe da filha, pois acreditava que Daiana tinha bastante necessidade de sua presença por ser ainda muito pequena: "Ontem fui chorando no ônibus, porque fui procurar emprego e acho que ela é muito nova para ficar sozinha!". Outra fonte de preocupação nesses momentos era a forma como os familiares cuidavam de Daiana: "Eu peço para mostrar bonequinho, conversar, mas ninguém fala com a guria, só pegam ela no colo e ficam olhando! Que criança vai gostar disso?".

Os sentimentos de angústia e preocupação parecem ter diminuído ao longo do tempo. Na entrevista de 8 meses, Simone não estava trabalhando e raramente separava-se da filha. Assim, falou pouco sobre seus sentimentos ligados à separação ao bebê, enfatizando mais as dificuldades da filha conforme mencionado anteriormente.

Crenças e práticas parentais relacionados a outros cuidados alternativos: Simone demonstrou, desde a gravidez, desejar dividir os cuidados da filha com outros cuidadores. Aos 3 meses, quando saía para procurar emprego, deixava o bebê aos cuidados das irmãs. No entanto, caso conseguisse um emprego, planejava deixar a filha com uma vizinha que julgava uma cuidadora bastante adequada:

"Vou deixar ela com uma menina que cuida muito bem. Ela é muito carinhosa, ela trata o filho dela assim, e eu vou deixar com ela porque ela conversa, ela ensina, a Daiana vai se acostumando já com outra pessoa". No oitavo mês, era Simone quem cuidava integralmente da filha, com a ajuda eventual de familiares. Contou que trabalhou temporariamente e sua irmã de 12 anos cuidou de Daiana. A mãe demonstrou satisfação com o cuidado oferecido por ela, mas julgava que os demais familiares eram pouco disponíveis. De maneira geral, Simone não se incomodava com a participação dessas pessoas.

Atitudes em relação à creche: Desde a gravidez, até o momento anterior ao ingresso de Daiana na creche, Simone era pouco favorável a inserir a filha nesse contexto. $\mathrm{Na}$ gestação, por exemplo, disse: "Sempre comigo, nada de creche! Pelo menos até o tempo de amamentação que é seis meses". Simone parecia preferir o ambiente de cuidado familiar à creche: "Entre a creche e deixar com minha irmã eu preferia deixar com a minha irmã. Porque não gosto de creche!". Essa rejeição pode estar ligada a sua própria experiência na infância: "Só lembro daquela imagem, de ela [avó materna] nos largar no portão e daí depois de uns três ou quatro dias ela voltava! E a gente ficava uma semana na creche!".

Quando Daiana tinha 3 meses, Simone nada mencionou sobre a creche. Já aos 8, pareceu ter se tornado mais favorável, mesmo enfatizando a importância de que a instituição fosse de boa qualidade: "Quero deixá-la numa creche boa, porque tem uma ali que é muito ruim, que é suja, é cheia, é um lugar que quando eu fui ver para a Daiana não me agradou, porque se eu tivesse simpatizado eu teria deixado ela, porque eu ia sentir segurança". Contudo, sua preferência ainda eram os cuidados oferecidos pela irmã.

Sentimentos relacionados ao ingresso do bebê na creche: Ao narrar a experiência da filha na creche, Simone falou pouco sobre seus sentimentos. Não demonstrou qualquer incômodo com a postura da instituição, mesmo tendo relatado que Daiana havia sido expulsa da creche. A mãe, ainda assim, tinha uma percepção positiva da instituição e a comparava com outra creche que ela considerava de má qualidade: "Era uma creche que gostei, já à primeira vista gostei das tias, do ambiente. Porque teve uma que nem com as tias, nem com a diretora eu simpatizei, achei elas com cara de más".

\section{Caso 4 - "Maternidade ou trabalho?"}

Caracterização: Gustavo era filho de um casal de namorados que, logo após o rompimento, soube da gravidez e decidiu reatar (mãe, 27 anos, ensino superior incompleto, vendedora. Pai, 26 anos, ensino superior incompleto, corretor de seguros). No primeiro ano do bebê o maior dilema da mãe referia-se a voltar a trabalhar ou ficar com o filho. Com 1 ano, foi para a creche, a qual a mãe considerava um ambiente organizado e favorável ao desenvolvimento da criança. Com essa experiência, Gustavo mostrou-se irritado e agressivo, o que levou os pais a tirá-lo da creche após 15 dias.

Temperamento do bebê: Aos 3 meses de Gustavo, pai e mãe o percebiam esperto e tranquilo, mesmo que às vezes fosse "bem birrento, quando ele não quer alguma coisa ele grita e chora!" (pai). Nesse momento, os pais afirmaram que Gustavo já não chorava mais de cólica à noite e tinha horários regulares para dormir, embora seu sono fosse agitado. Quanto à amamentação, ele era alimentado de duas em duas horas e tinha dificuldades em aceitar novos alimentos. Era um bebê tranquilo com outras pessoas.

Aos 8 meses, Gustavo continuava mamando no peito, passou a comer uma grande variedade de alimentos, porém em pouca quantidade. Os pais percebiam que ele vomitava e não ganhava muito peso, o que posteriormente foi diagnosticado como refluxo. $\mathrm{O}$ sono se mantinha agitado, mas ele continuava bem humorado, esperto, chorava pouco e gostava de estar com outras pessoas. Os pais notavam no filho 
uma curiosidade de explorar novas situações e brinquedos, algo que a mãe incentivava: "O Gustavo me mostra que ele tem que conhecer o mundo e acho isso bom". Além disso, os pais percebiam que o filho sabia o que queria, e que "se tu não fazes o que ele quer, ele briga contigo" (pai).

Sentimentos ligados à separação pais-bebê e à inclusão de outras pessoas no dia a dia da criança: Aos 3 meses, a mãe relatou estar sofrendo em relação à separação de Gustavo, uma vez que ela voltara a trabalhar: "Fico passando esta angústia de que eu não quero trabalhar, eu quero ficar com ele!". Nesse momento, a avó paterna era quem cuidava do bebê, mas a mãe não gostava da forma como ela o fazia. Também se sentia incomodada com a constante interferência de sua mãe e do companheiro em sua relação com o filho, o que aumentava sua insegurança em relação às decisões sobre o bebê. Além disso, se ressentia porque estava perdendo alguns acontecimentos do desenvolvimento de Gustavo: "Ontem ele comeu a primeira sopa da vida dele e eu não vi!".

No oitavo mês, a mãe havia parado de trabalhar e relatou que suas dificuldades em separar-se do filho continuavam, de modo que ela não o deixava sozinho com ninguém. Desejava ter autonomia para cuidar do filho, sem a intrusão de outras pessoas, e pensava em voltar a trabalhar quando Gustavo estivesse falando e andando. No entanto, com o passar do tempo, começou a sentir vontade de fazer outras atividades e procurou uma psicóloga para ajudá-la nesse processo. Decidiu colocá-lo na creche e trabalhar como vendedora autônoma, sem horários fixos, de modo a poder continuar com o filho nas horas vagas.

Crenças e práticas parentais relacionados a outros cuidados alternativos: Na gestação, Denise já planejava a participação de sua mãe nos primeiros cuidados com o filho, embora não desejasse que esta ajuda se prolongasse, pois receava uma intromissão excessiva e de que ela o mimasse demais. Quando Denise voltou a trabalhar, o pai se revezava nos cuidados com as avós. O casal mostrou uma incerteza muito forte quanto à escolha dos cuidados ao filho: " $A$ princípio pensamos em contratar alguém enquanto estamos no trabalho, ou tem a possibilidade de ela sair do emprego e ficar mais um tempo junto com ele, até ele ficar maiorzinho. Essa é a dificuldade maior, de saber o que a gente vai fazer, o que vai ser melhor para ele, o que vai ser melhor para nós!" (pai). Aos 8 meses, quando Denise não estava trabalhando, as avós faziam parte dos cuidados, geralmente na companhia da mãe, e raramente Denise saía e deixava Gustavo com a avó paterna.

Atitudes em relação à creche: Durante a gestação os pais já consideravam a creche uma opção de cuidado, pois, para o pai, ela ajudaria na socialização do filho. Aos 3 meses, os pais relataram que não gostariam de colocá-lo na creche no primeiro ano de vida, já que consideravam o ambiente familiar mais adequado. Inclusive, essa orientação foi dada pelo pediatra. Denise chegou a visitar algumas creches, mas não gostou dos ambientes que viu, ficando com a impressão de que o filho não seria bem cuidado. Os pais pensavam que o melhor momento para Gustavo entrar na creche seria quando ele começasse a falar e caminhar, e, então, pudesse se defender.

No oitavo mês, a mãe se referiu à creche com repúdio, como se as mães que lá deixavam os filhos não fossem boas mães. Assim, Denise desistiu de trabalhar e decidiram postergar o ingresso na creche: "Até ele fazer um aninho eu acho importante ela estar em casa com ele. É que também tem o fato de ele ser muito apegado com ela. Mas eu acho que tudo bem, é pequeninho ainda, está no colinho" (pai). Denise acreditava que Gustavo não reagiria bem ao ingresso na creche, pois, para ela, "na creche ele não vai ser bem cuidado".

Sentimentos ligados ao ingresso do bebê na creche: Os pais relataram que ficaram surpresos pela reação negativa do filho, que chorava bastante. A mãe disse ter sofrido junto com o filho: "Se agarrava em mim e era horrivel, eu chorei também, milhares de vezes lá na porta, para mim foi uma experiência horrivel". Ela contou que sentia que o estava maltratando, uma vez que de fato ele não precisaria estar na creche. Inclusive os pais perceberam que o filho havia mudado: "Na fase que ele estava lá na creche ele chegava em casa com uma raiva do mundo, ele só batia na cara de todo mundo. O Gustavo nunca fez isso na vida".

\section{Discussão}

Optou-se por discutir inicialmente os resultados referentes a cada categoria de análise, considerando, em conjunto, os quatro casos estudados. Em um segundo momento, apresentam-se algumas considerações finais que transcendem as próprias categorias. Além disso, ao longo da discussão, foram examinados tanto os pontos em comum entre os casos, quanto suas especificidades.

No que diz respeito ao temperamento do bebê, alguns estudos têm indicado que crianças com temperamento difícil parecem apresentar mais dificuldades na adaptação (Ahnert et al., 2004; Fein, 1995; Klein, 1991; Rapoport \& Piccinini, 2001b). No entanto, no presente estudo, verificou-se que, apenas no Caso 1, o bebê foi claramente descrito como apresentando um temperamento mais difícil. Mesmo antes do ingresso na creche, seu temperamento parece ter influenciado o estilo de interação com os pais (e vice-versa), de modo que esses procuravam estar o mais próximos possível do filho, visando responder rapidamente às suas necessidades, as quais julgavam que não poderiam ser supridas por outras pessoas.

Assim, é possível se pensar que a influência do temperamento do bebê na adaptação à creche é mediada pelas representações parentais a respeito do filho, pelas interações entre eles e pelas estratégias que os pais utilizam para lidar com as demandas do bebê antes mesmo do ingresso na creche. No Caso 1, em particular, os pais pareciam não acreditar que outras pessoas pudessem adaptar-se às necessidades do filho, o que pode ter contribuído para as dificuldades que a criança enfrentou na interação com as educadoras e até na própria decisão por retirá-lo da creche.

Essas ideias também são corroboradas pelos resultados referentes ao Caso 3, no qual foi possível constatar que a modulação das reações da criança pela mãe foi diferente 
daquela apresentada pelos pais do Caso 1. No Caso 3, a mãe tinha extrema dificuldade de identificar as necessidades da filha e de acalmá-la, de modo que a deixava chorar por muito tempo e, chegava até mesmo a ser agressiva com a menina. Nesse sentido, as reações de protesto mais intensas e prolongadas da filha no ambiente doméstico e na creche poderiam estar ligadas a uma sensação de desamparo e insegurança diante da instabilidade nos cuidados, sugerindo a existência de um padrão de apego mais inseguro. Isso está de acordo com o estudo de Ahnert et al. (2004), o qual verificou que crianças com apego seguro foram percebidas pela mãe como mais acessíveis e adaptáveis a novas situações do que as crianças com apego inseguro.

A segunda categoria de análise explorada neste estudo referiu-se aos sentimentos parentais ligados à separação pais-bebê. Muitas vezes, o ingresso na creche representa a primeira separação mais prolongada entre pais e bebês. Assim, para compreender a adaptação do bebê, é importante que se conheça também as experiências prévias de separação e a forma como os pais vivenciam esses episódios (Burchinal et al., 1992; Ferreira, 2007). Dentre os casos estudados no presente estudo, os Casos 1 e 4 parecem ter sido os mais fortemente influenciados pelas dificuldades de separação pais-bebê. Por exemplo, no Caso 1, pai e mãe referiam uma dificuldade explícita de separar-se do bebê e, poucos meses antes de colocá-lo na creche, admitiam que ainda não conseguiam deixá-lo sob cuidados exclusivos de outras pessoas. Já no Caso 4, o dilema de separação apareceu desde a gestação, quando a mãe já se mostrou ambivalente quanto à ênfase no trabalho ou na vida familiar.

É interessante destacar que, em ambos os casos, a opção por inserir o bebê na creche esteve atrelada à percepção das mães de que ou a criança (Caso 1) ou a própria mãe (Caso 4) apresentavam necessidade de maior autonomia e independência, em torno do final do primeiro ano da criança. Dessa forma, assim como no estudo de Bellini (2008), a escolha pela creche pareceu estar ligada ao processo de separação mãe-bebê. Esse processo, segundo Lopes et al. (2007), tende a ser vivido de forma ambivalente pelas mães, que se sentem gratificadas pelo desenvolvimento do filho, mas também enlutadas pela perda da proximidade mais intensa com o bebê. No entanto, nos dois casos referidos, as mães demonstraram uma dificuldade mais intensa de lidar com o processo gradual de separação, de modo que a decisão pela creche pareceu repentina e pouco planejada, e talvez tenha sido percebida pelas mães como a única forma de promover a separação.

Verificou-se também que, nos Casos 1 e 4, a forma como os pais vivenciaram o processo de separação pareceu relacionar-se às suas crenças e práticas ligadas aos cuidados alternativos. Por exemplo, no Caso 1, os pais optaram por cuidar sozinhos da criança, enquanto no Caso 4 a mãe considerava importante que o filho tivesse contato com outras pessoas, mas tinha dificuldades de deixá-lo sozinho com elas. Na verdade, alguns estudos têm indicado que a adaptação é favorecida pelo fato de a criança ter sido cuidada por outras pessoas que não apenas o(s) cuidador(es) primário(s) (Aloa, 2008; Blanchard \& Main, 1979; Schipper et al., 2004). Contudo, no presente estudo, somente no Caso 1 a criança não havia tido essa experiência, o que pode ter contribuído para suas dificuldades em permanecer na creche. Por outro lado, é importante que se analise não somente a experiência concreta da criança com outras crianças e cuidadores, mas também as crenças dos pais sobre os cuidados alternativos. Isso porque, muitas vezes, os pais deixam a criança com outras pessoas por necessidade, mas não se sentem confortáveis com essa decisão, o que aconteceu principalmente nos casos 2 e 4 .

No Caso 2, em especial, a relação dos pais com os cuidadores alternativos foi bastante central para a compreensão da escolha pela creche e também para a não permanência da criança. A participação excessiva dos avós nos cuidados do bebê, sentida como intrusão pelos pais, pareceu intensificar a insegurança deles frente à criação da filha. Assim, o ingresso na creche representou para os pais uma possibilidade de distanciamento em relação aos familiares - que eram desfavoráveis à creche - e também de tomarem uma decisão de forma independente, ainda que não completamente seguros. Isso, porém, não se sustentou quando a criança manifestou as primeiras reações ao ingresso na creche e, após uma semana, os pais voltaram atrás na sua decisão. Para Rossetti-Ferreira et al. (1996), se a mãe já sai de casa em conflito quanto leva o bebê à creche, influenciada por familiares que não concordam com este tipo de cuidado, pode vir a sentir-se descuidada e má em relação ao filho, principalmente se o reencontra chorando e adoecido. Assim, uma estratégia que pode contribuir nesse momento é permitir que as mães conheçam algumas das reações esperadas do bebê no ingresso à creche, o que pode facilitar para que a adaptação transcorra de forma mais tranquila (Ferreira, 2007).

Com relação à quarta categoria analisada, sobre as atitudes dos pais relacionadas à creche, os resultados revelaram que, nos quatro casos, as opiniões a respeito de colocar ou não o bebê na creche modificaram-se bastante ao longo dos primeiros meses do bebê. Verificou-se que os pais tornaram-se menos favoráveis à creche, pelo menos entre a gestação e o primeiro ano de vida do bebê, e, mesmo meses antes da decisão por inserir o filho na instituição. A maior parte deles acreditava nos benefícios da interação com outras crianças, porém não se sentia segura quanto à qualidade dos cuidados oferecidos pela creche.

Em uma revisão de literatura, Rapoport e Piccinini (2004) constataram que optar por uma forma de cuidado alternativo não é tarefa fácil para os pais. Eles têm dúvidas sobre o tipo de cuidado e a melhor idade para inserir a criança. A literatura não retrata consenso sobre a melhor forma de cuidado alternativo e nem sobre todos os seus efeitos no desenvolvimento infantil, embora aponte alguns indícios de que instituições de boa qualidade podem contribuir na promoção do desenvolvimento da criança (Burchinal et al., 2000; Marshall, 2004; Melhuish, 2004). No entanto, no Brasil, apesar de existirem diretrizes específicas para a educação infantil (Brasil, 1998) e para a avaliação de sua qualidade (Brasil, 2009), não há uma prática regular e padronizada de avaliação da qualidade das instituições e de orientação e suporte às famílias com crianças pequenas. Esses aspectos, atrelados a dificuldades individuais dos pais, parecem contribuir para sua insegurança e, até mesmo, para a opção de retirar a criança da instituição. 
Por fim, é importante também destacar que os sentimentos despertados nos pais depois que a criança entra na creche influenciam a adaptação. No presente estudo, percebeu-se que, em todos os casos, as reações da criança na adaptação mobilizaram os pais de forma muito intensa, sobretudo seu choro. Esse sinal foi considerado pelos pais um importante indicador de não adaptação. Na verdade, o choro tende a ser bastante comum entre crianças em período de adaptação, principalmente na chegada e na saída à creche (Pantalena, 2010; Rapoport \& Piccinini, 2001a); e tende a ser mais intenso entre as crianças que estão no segundo semestre de vida (Aloa, 2008; Kearsley et al., 1975, Rodriguez, 1981). Estudos têm mostrado que mesmo quando o choro é visto como natural e esperado no processo de adaptação, incomodava as mães e era percebido como sinal de que algo negativo poderia estar acontecendo (Ferreira, 2007; Pantalena, 2010). Porém, ao avaliar o processo de adaptação não se deve levar em conta apenas o choro, mas também outras reações da criança, como o sono, a alimentação, a interação social e a exploração do ambiente, que se constituem em indicadores que também podem auxiliar na avaliação da adaptação do bebê.

Os resultados do presente estudo também revelaram que, quanto mais intensas as reações da criança após o ingresso na creche, mais os pais sentiram-se culpados por sua decisão. Assim, principalmente nos casos 1 e 4, a brusca separação foi sentida e relatada como abandono, por parte das mães, com as crianças protestando com o choro, não se alimentando, adoecendo e apresentando comportamentos agressivos.

Isso também sugere a importância de um apoio especial ao cuidador que está presente no período de adaptação, já que ele, ao ser mediador das primeiras interações entre o bebê e educadora/creche, pode facilitar ou dificultar a transição (Pantalena, 2010; Rossetti-Ferreira et al., 1996; Strenzel, 2002). Além disso, essa mediação pode incluir o encorajamento da independência da criança (Davies, 1991), o que nem sempre é fácil para os pais.

De maneira geral, os resultados do presente estudo indicaram que os fatores mais relevantes para a compreensão da não adaptação à creche foram os ligados à dinâmica da interação pais-bebê: os sentimentos ligados à separação pais-bebe e a forma como os pais vivenciaram o ingresso na creche. No entanto, destaca-se que outros fatores também foram importantes em alguns dos casos analisados, que podem também ter potencializado as reações dos pais e crianças na adaptação. Frente a um contexto tão complexo como o da adaptação de bebês à creche, não se pode pensar linearmente, assumindo fatores específicos como determinando o processo. Existe, obviamente, um conjunto de fatores, desde os mais explícitos aos mais subjetivos, que interagem na adaptação. Ademais, no presente estudo, a análise longitudinal permitiu verificar que a transição para a creche é influenciada por elementos presentes desde os primórdios da interação pais-bebê, e antes mesmo desta, na própria gestação. Assim, ressalta-se a relevância de ações anteriores ao ingresso na creche que promovam um acolhimento à situação de separação pais-bebê e que considerem um conjunto de fatores potencialmente importantes para a adaptação, entre eles os aspectos do desenvolvimento emocional do bebê no contexto familiar.
Por fim, considera-se que, para uma compreensão mais completa do processo de não permanência na creche, seria importante analisar também a qualidade do atendimento na instituição e, particularmente, as estratégias utilizadas pela creche no período de transição. Nesse sentido, novos estudos poderão explorar de forma mais detalhada como as creches vêm lidando com as particularidades dos bebês e das demandas familiares, o que poderá contribuir para este período de transição, que tem implicações muito importantes para o desenvolvimento da criança e de suas relações na família e na creche.

\section{Referências}

Ahnert, L., Gunnar, M. R., Lamb, M. E., \& Barthel, M. (2004). Transition to child care: Associations with infant mother attachment, infant negative emotion, and cortisol elevations. Child Development, 75, 639-650.

Aloa, V. (2008). Infants settled in to care: More than attachment. Adelaide: Flinders University of South Australia.

Bardin, L. (1977). Análise de conteúdo. L. Reto, \& A. Pinheiro, (Trans.). São Paulo: Edições 70/Livraria Martins Fontes.

Bellini, L. (2008). A vivência materna do processo de separaçãoindividuação mãe bebê do primeiro ano de vida até a entrada na creche (Unpublished master's thesis). Universidade Federal do Rio Grande do Sul, Porto Alegre.

Blanchard, M., \& Main, M. (1979). Avoidance of the attachment figure and social-emotional adjustment in day care infants. Developmental Psychology, 15, 445-446.

Brasil. Ministério de Educação e do Desporto. (1998). Referencial curricular nacional para educação infantil. Brasília, DF: MEC.

Brasil. Ministério da Educação e do Desporto. (2009). Indicadores da Qualidade na Educação Infantil. Brasília: Secretaria de Educação Fundamental.

Burchinal, M., Bryant, D., Lee, M., \& Ramey, C. (1992). Early day care, infant-mother attachment, and maternal responsiveness in the infant's first year. Childhood Research Quarterly, 7, 383-396.

Davies, J. (1991). Children's adjustment to nursery class: How to equalize opportunities for a successful experience. School Organization, 11(3), 255-262.

Fein, G. G. (1995). Infants in group care: Patterns of despair and detachment. Early Childhood Research Quarterly, 10, 261-275.

Ferreira, G. V. (2007). O impacto da adaptação de crianças na creche sobre os sentimentos maternos (Monografia de Especialização não publicada). Universidade Federal do Rio Grande do Sul, Porto Alegre.

Grupo de Interação Social, Desenvolvimento e Psicopatologia GIDEP (1998a). Entrevista de dados demográficos do casal. Universidade Federal do Rio Grande do Sul, Porto Alegre.

Grupo de Interação Social, Desenvolvimento e Psicopatologia GIDEP (1998b). Entrevista sobre a Gestação e Expectativas da Gestante. Universidade Federal do Rio Grande do Sul, Porto Alegre.

Grupo de Interação Social, Desenvolvimento e Psicopatologia GIDEP (1998c). Entrevista sobre a gestação e as expectativas do futuro pai. Universidade Federal do Rio Grande do Sul, Porto Alegre. 
Grupo de Interação Social, Desenvolvimento e Psicopatologia - GIDEP (1999a). Ficha de impressões dos pais sobre o temperamento da criança. Universidade Federal do Rio Grande do Sul, Porto Alegre.

Grupo de Interação Social, Desenvolvimento e Psicopatologia GIDEP (1999b). Entrevista sobre a experiência da maternidade e o desenvolvimento do bebê no primeiro trimestre. Universidade Federal do Rio Grande do Sul, Porto Alegre.

Grupo de Interação Social, Desenvolvimento e Psicopatologia - GIDEP (1999c). Entrevista sobre a experiência da paternidade e o desenvolvimento do bebê no primeiro trimestre. Universidade Federal do Rio Grande do Sul, Porto Alegre.

Howes, C. (1990). Can the age of entry into child care and the quality of child care predict adjustment in kindergarten? Developmental Psychology, 26(2), 292-303.

Kearsley, R. B., Zelazo, P. R., Kagan, J., \& Hartman, R. (1975). Separation protest in day care and home reared infants. Pediatrics, 55, 171-175.

Klein, H. A. (1991). Temperament and childhood group care adjustment: A cross-cultural comparison. Early Childhood Research Quarterly, 6, 211-224.

Laville, C. \& Dionne, J. (1999). A construção do saber. Manual de metodologia da pesquisa em ciências humanas. Porto Alegre: Editora UFMG/Artmed.

Lopes, R. C. S., Oliveira, D. S., Vivian, A. G., Bohmgahren, L. M. C., Piccinini, C. A., \& Tudge, J. (2007). Sentimentos maternos frente ao desenvolvimento da criança aos 12 meses: convivendo com as novas aquisições infantis. Psicologia: Teoria e Pesquisa, 23(1), 5-16.

Marshall, N. L. (2004). The quality of early child care and children's development. Current Directions in Psychological Science, 13(4), 165-168.

Melhuish, E. C. (2004). A literature review of the impact of early years provision upon young children, with emphasis given to children from disadvantaged backgrounds: Report to the Comptroller and Auditor General. London: National Audit Office.

Pantalena, E. S. (2010). O ingresso da criança na creche e os vinculos iniciais (Unpublished master's thesis). Universidade de São Paulo, São Paulo.

Piccinini, C. A., Gomes, A. G., Moreira, L. E., \& Lopes, R. C. S. (2004). Expectativas e sentimentos da gestante em relação ao seu bebê. Psicologia: Teoria e Pesquisa, 20(3), 223-232.
Piccinini, C. A., Tudge, J. R., Lopes, R. C., \& Sperb, T. (2009). Projeto Longitudinal de Porto Alegre: da Gestação à Escola (Projeto não publicado). Universidade Federal do Rio Grande do Sul, Porto Alegre.

Rapoport, A. (2003). Da gestação ao primeiro ano de vida do bebê: Apoio social e ingresso na creche (Unpublished doctoral dissertation). Universidade Federal do Rio Grande do Sul, Porto Alegre.

Rapoport, A. \& Piccinini, C. A. (2001a). O ingresso e adaptação de bebês e crianças pequenas à creche: alguns aspectos críticos. Psicologia: Reflexão e Crítica, 14(1), 81-95.

Rapoport, A. \& Piccinini, C. A. (2001b). Concepções de educadoras sobre a adaptação de bebês à creche. Psicologia: Teoria e Pesquisa, 17(1), 69-78.

Rapoport, A., \& Piccinini, C. A. (2004). A escolha do cuidado alternativo para o bebê e a criança pequena. Estudos de Psicologia, 9(3), 497-503.

Rodriguez, D. T. (1981). Infant day care: How very young children adapt. Children Today, 10-12.

Rossetti-Ferreira, M. C., Amorin, K. S., \& Vitória, T. (1996). Emergência de novos significados durante o processo de adaptação de bebês à creche. In M. I. Pedrosa (Ed.), Investigação da criança em interação social, Coletâneas da ANPEPP, 4(1), 111-144.

Schipper, J. C. D., van IJzendoorn, M. H., \& Tavecchio, L. W. C. (2004). Stability in center day care: Relations with children's well-being and problem behavior in day care. Social Development, 13, 531-550.

Stake, R. (1994). Case Studies. In N. Denzin, (Ed.), Handbook of Qualitative Research (pp. 435-454). London: Sage.

Strenzel, G. R. (2002). Tempo de chegada na creche: conhecendo-se e fazendo-se conhecer. Revista Zero a Seis. Seção Cotidiano na Educação Infantil, 6.

Recebido em 04.02.2013

Primeira decisão editorial em 04.09.2013

Versão final em 08.10.2013

Aceito em 29.10.2013 